\section{Apoptosis (cPARP)}
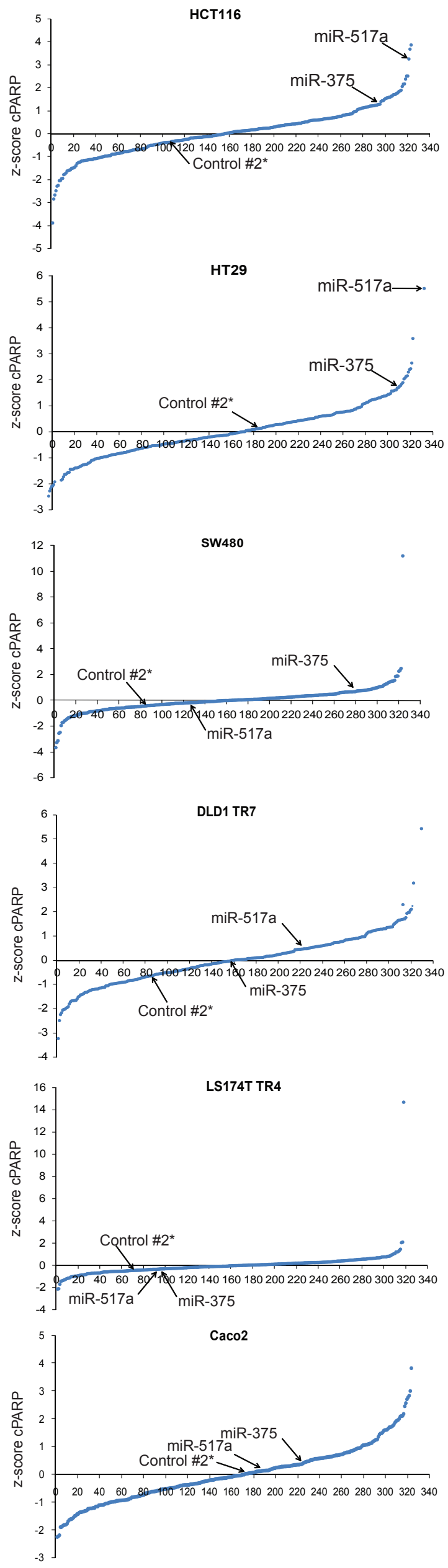

Proliferation (Ki67)

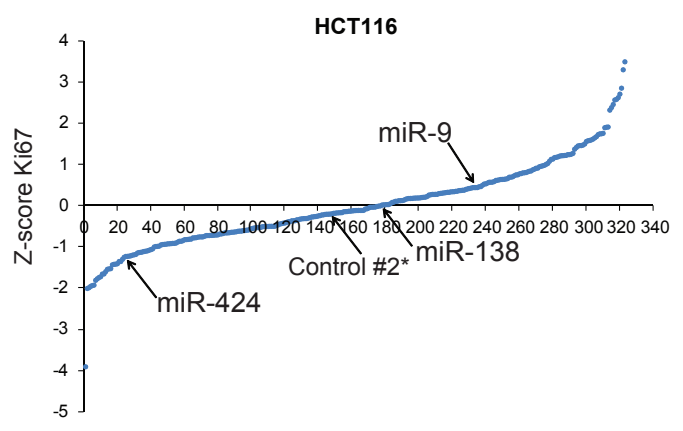

HT29

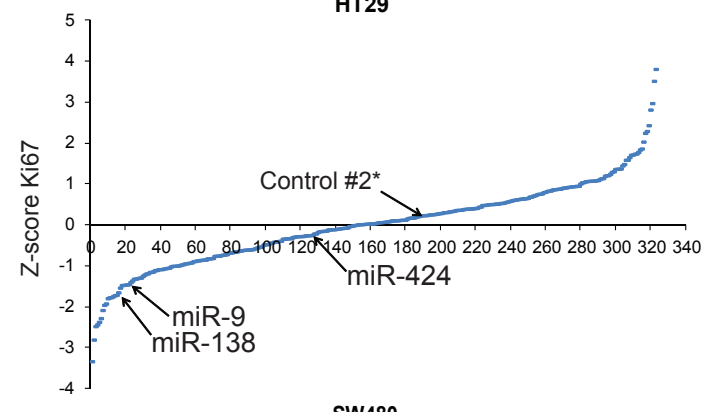

SW480

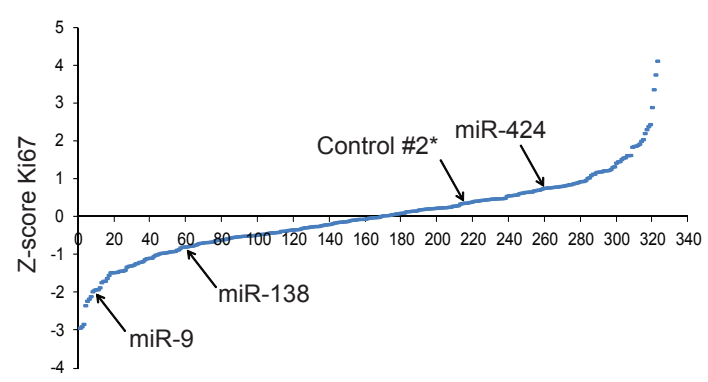

DLD1 TR7

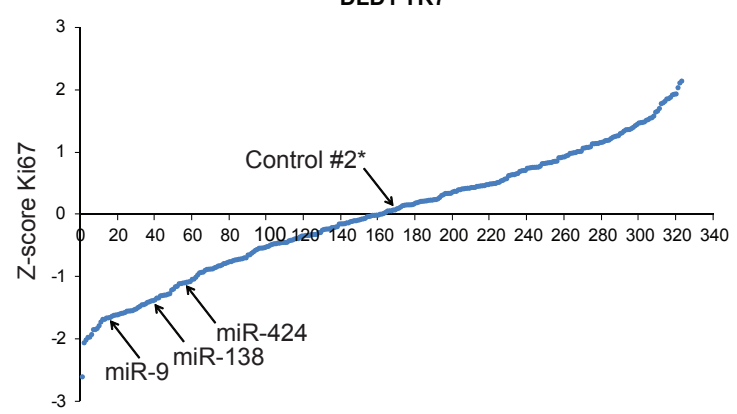

LS174T TR4
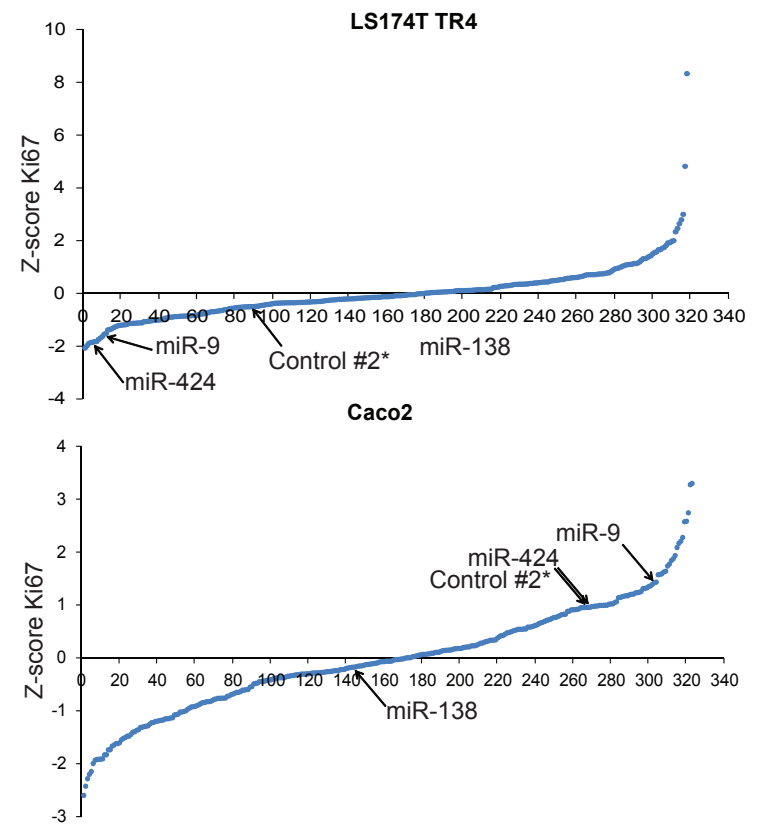

Supplementary Fig. S1. Line graph distributions of the cPARP and Ki67 z-scores for each pre-miR in six CRC cells lines. Selected miRNAs are shown. ${ }^{*}$ Pre-mir negative control \#2 